\title{
OUTDOOR AIRFLOW INTO HVAC SYSTEMS: AN EVALUATION OF MEASUREMENT TECHNOLOGIES
}

\author{
William J. Fisk, David Faulkner, Douglas P. Sullivan, and Woody Delp \\ Indoor Environment Department \\ Environmental Energy Technologies Division \\ Lawrence Berkeley National Laboratory \\ Berkeley, CA 94720
}

September 24, 2003

This work was supported by the Assistant Secretary for Energy Efficiency and Renewable Energy, Building Technologies Program of the U.S. Department of Energy under Contract DEAC03-76SF00098. 


\title{
OUTDOOR AIRFLOW INTO HVAC SYSTEMS: AN EVALUATION OF MEASUREMENT TECHNOLOGIES
}

\author{
William J. Fisk, David Faulkner, Douglas P. Sullivan, and Woody Delp \\ Indoor Environment Department \\ Environmental Energy Technologies Division \\ Lawrence Berkeley National Laboratory \\ Berkeley, CA 94720
}

\begin{abstract}
During the last few years, new technologies have been introduced for measuring the flow rates of outdoor air (OA) into HVAC systems; however, an evaluation of these measurement technologies has not previously been published. This document describes a test system and protocols developed for controlled evaluation of these measurement technologies. The results of tests of three measurement technologies are also summarized. The test system and protocol were judged practical and very useful. The test results indicate that one measurement technology can measure OA flow rates with errors of $20 \%$ or less without a field-based calibration, as long as the OA velocities are sufficient to provide an accurately measurable pressure signal. The test results for a second measurement technology are similar; however, a difficult field-based calibration relating the OA flow rate with the pressure signal would be required to reduce errors below approximately $30 \%$. The errors in OA flow rates measured with the third measurement technology, that uses six electronic airspeed sensors downstream of the OA inlet louver, exceeded 100\%; however, these errors could be substantially reduced through a difficult field based calibration. The effects of wind on the accuracy of these measurement technologies still needs to be evaluated.
\end{abstract}

\section{Background}

Ventilation, i.e., providing outdoor air (OA), has a substantial influence on building energy consumption, occupant health, and occupant satisfaction with the indoor environment. The quantity of energy used for ventilation in the U.S. service sector (i.e., commercial, institutional, and government buildings) is uncertain, but clearly substantial. Orme (1998) estimated that the energy consumed to ventilate these buildings is 1.4 Quad (1.5 EJ), which is approximately one quarter of the total service-sector building energy use; however, this estimate is likely to be too high because it assumes continuous occupancy. Through more detailed analyses with estimates of actual periods of occupancy, Emmerich and Persily (1998) predicted that 0.13 Quad (0.14 EJ) of heating and cooling energy would be used for ventilating U.S. office buildings, if all offices had a ventilation rate of $20 \mathrm{cfm}\left(10 \mathrm{~L} \mathrm{~s}^{-1}\right)$ per person. Applying the ventilation energy use per unit floor area of Emmerich and Persily (1998) to the entire stock of U.S. service sector buildings yields an estimated energy consumption for ventilation of 0.71 Quad (0.75 EJ) for the entire stock. We expect that the actual energy use is considerably higher, i.e., between 0.71 and 1.4 Quad ( 0.75 and $1.5 \mathrm{EJ})$, because many types of service sector buildings have a higher occupant density or are ventilated for longer periods of each day than offices.

The scientific literature describing the influence of ventilation rates on health and occupant satisfaction was reviewed by Seppanen et al. (1999). On average, lower ventilation rates were associated with increased prevalences of communicable respiratory illnesses (e.g., common colds), increased prevalences of sick building syndrome (SBS) symptoms, and diminished satisfaction with indoor air quality. A large majority of studies reviewed found statistically significant and substantial $(10 \%$ to $>100 \%)$ increases in 
health outcome prevalences with lower ventilation rates. The evidence of adverse effects was strongest when ventilation rates were reduced below $20 \mathrm{cfm}\left(10 \mathrm{~L} \mathrm{~s}^{-1}\right)$ per person, which is the current minimum rate for offices in ASHRAE Standard 62 (ASHRAE 2001); however, several studies reported benefits of increasing ventilation rates above $20 \mathrm{cfm}\left(10 \mathrm{~L} \mathrm{~s}^{-1}\right)$ per person.

Despite the substantial influences of ventilation rates on energy use and health, very few U.S. buildings have an integral system for measuring ventilation rates. The typical practice ${ }^{1}$ in office and institutional buildings, which are the primary focus of this report, is to have an air balance company measure the OA flow during a period of building commissioning or airflow balancing and adjust the positions of the dampers for OA, recirculation air, and exhaust air to obtain the desired minimum rate of OA supply. However, accurately measuring OA airflow into HVAC systems is technically challenging and typical practices often do not satisfactorily determine minimum ventilation rates. For example, the minimum OA flow is sometimes based on the difference between supply and return air flow rates, with each of these flow rates determined using an air flow measuring station in the airstream ${ }^{2}$. Even with perfect measurements, the estimate will often not be valid because there is significant airflow through the exhaust damper system (Krarti et al. 1999). Also, modest errors in measurements of supply and return air flow rates can produce a large error in the difference between these two flow rates (Kettler 1995).

An alternative method for measuring OA flows is a velocity traverse with a rotating vane anemometer at the exterior face of the outdoor air inlet. However, the non-stable (due to winds) and spatially nonuniform air velocities at the outdoor air intakes, plus the difficulty in determining the effective area of the intake can result in large errors (Howell et al. 1987, Krarti et al. 1999).

Another alternative measurement approach is to determine the outdoor airflow from the product of a measured supply airflow rate and the percentage of outdoor air (\%OA) in the supply air stream, which is determined from air temperature measurements and an energy balance calculation. However, nonuniform airstream temperatures and small differences between temperatures can cause large errors in the estimated \%OA and associated OA flow rate (Krarti et al. 1999).

Even if air balance professionals could provide perfect measurements of OA flow rates during their occasional visits to buildings, the OA flow is not stable. The actual rates of OA flow will often vary with changes in wind and as the supply air flow rates of variable air volume (VAV) HVAC systems are modulated. In addition, minimum damper positions, which affect $\mathrm{OA}$ flow rates may change from those set by the air balance professional due to deliberate adjustments by building operators and to wear or failures in the damper actuators and linkage.

Given these measurement challenges it is not surprising that the ventilation rates measured in surveys by researchers using tracer gas based measurement systems (e.g., Turk et al. 1989, Lagus Applied Technologies 1995, Persily 1989) often differ substantially from the minimum ventilation rates specified in the applicable codes. Many buildings have minimum ventilation rates far exceeding code requirements. Routine use of OA measurement systems may be one of the most cost-effective methods of reducing energy use in these over ventilated buildings. A significant but smaller portion of buildings provide less ventilation than specified in codes and OA measurement systems could reduce IAQ problems

\footnotetext{
${ }^{1}$ In some larger buildings, a separate OA injection fan is used to provide minimum OA. The injection fan could have an accompanying system for measuring OA flow rates.

${ }^{2}$ In some buildings, the OA flow scheme is based on a method called "return fan tracking". As the flow through the supply fan changes, the system adjusts the return fan speed in an attempt to maintain a fixed difference in flow rate. As discuused by Schroeder, in practice return fan tracking often maintains the OA flow needed to maintain the building pressurized, which does not necessarily equal the recommended minimum OA supply rate. (Schroeder et al. 2000). This method also fails if the exhaust flow rate is non-zero during minimum OA supply
} 
associated with insufficient ventilation. In some buildings, OA flows and associated building pressures are very poorly controlled. For example, in our field studies it has not been unusual to find indoor air flowing to outdoors through the OA intake louvers and dampers.

There are significant obstacles to cost-effective and accurate measurements of OA flow rates. First, measurements are challenging because OA intake velocities are intentionally kept low in order to minimize rain and snow from being drawn into the air handler. Sizing of the OA air inlet for the entire OA flow into the air handler during economizer operation compounds the problem. The result is particularly low OA intake velocities during periods of minimum OA supply, when measurements are most important. Based on a review of specifications of louvers, the maximum recommended air velocity within the "free area" of an intake louver is usually 700 to $2500 \mathrm{fpm}$ ( 3.5 to $\left.13 \mathrm{~m} \mathrm{~s}^{-1}\right)$ to minimize entrainment of rain and snow. These velocities occur with the maximum flow at the OA intake during economizer operation with $100 \%$ outdoor air. Since the minimum OA supply may be only $20 \%$ of the full supply air flow rate, the velocities of $\mathrm{OA}$ in the free area of the louver during periods of minimum OA flow will be only 140 to $500 \mathrm{fpm}\left(0.5\right.$ to $\left.2 \mathrm{~m} \mathrm{~s}^{-1}\right)$. Because the cross sectional area for flow inside the louver is less than the nominal face area of the louver, the velocities upstream of the outside air louver may be $30 \%$ to $50 \%$ of the velocities in the free area of the louver. At these low velocities the dynamic pressure, which is often used in to measure air speed, is only thousandths of an inch of water (a fraction of a Pascal), which is too low for accurate measurements in field settings.

The geometry of the OA intake and its impact on velocity profiles further complicates the measurements. The outdoor air passes through a bird screen, a set of louvers, and an adjustable OA damper. Downstream of the louvers or OA dampers the speed and direction of airflow will normally vary markedly across the flow cross section; thus, averaging velocity measurements made at a few locations in the cross section may also lead to large measurement errors. At the exterior face of the OA intake, measurements are problematic because even normal winds cause a large fluctuation in air velocity. To reduce the obstacles to measurements, components could be added that increase air velocities and straighten the flow downstream of the louvers or OA damper, with associated increases in costs and pressure drops. Also, large numbers of velocity sensors could be used to better assess the average velocity. However, practical measurement systems face cost, pressure drop, and space constraints.

While these problems and the need for better measurement and control of OA ventilation rates have been recognized for many years, until recently there has been little progress toward meeting this need. The review of Krarti et al. (1999) on measurement and control of OA flow in variable air volume systems includes a summary of much of the recent research. In particular, Krarti et al. (1999) point out that the long unobstructed OA ducts needed for most flow rate measurements will generally be impractical, and they identify a few more promising alternatives, including:

1. providing a separate outdoor air duct for the minimum outdoor airflow with air velocities maintained sufficiently high for use of Pitot-static tube arrays;

2. maintaining a constant pressure drop across the OA louvers and dampers during minimum outdoor air conditions; and

3. using a $\mathrm{CO}_{2}$ mass balance to compute the percentage of outdoor airflow (\%OA) and multiplying by the separately metered supply airflow to determine the outdoor airflow.

While each of these alternatives has merit, they also have some drawbacks. Alternative 1 (providing a separate OA duct) may be unattractive to designers because of space constraints and costs, especially for

\footnotetext{
${ }^{3}$ Minimum total cross sectional area for airflow through a louver.
} 
small to moderate size HVAC systems. Alternative 2 is a flow control strategy but requires a separate measurement system for calibration of flow versus pressure drop in field settings. Alternative 3, requires an accurate measurement system for supply flow rates and is not applicable when indoor $\mathrm{CO}_{2}$ concentrations are marginally above outdoor concentrations because of a low occupant density or because occupants arrived recently. Also, alternatives 1 and 2 only provide a measurement during minimum outdoor air supply.

Within the past few years, manufacturers have pursued another option -- the direct measurement of airflow through the OA intake using a sensor system located at the intake. A handful of related measurement technologies have emerged on the market within the last few years.

The objectives of the research discussed in this report are to: 1) evaluate the performance (accuracy and pressure drop) of these emerging direct measurement technologies; and 2) develop a test system and protocol for evaluating measurement system performance. After sufficient experience is gained, the test method developed in this research may serve as the initial basis for a standard test method of a professional organization such as ASHRAE or AMCA.

\section{Approach}

\section{Test system description}

The laboratory test system constructed for this research and illustrated diagrammatically in Figure 1, has a changeable OA intake louver and damper system, air recirculation ductwork, a variable speed fan, recirculation and exhaust dampers, and a precision "reference" airflow meter upstream of the location of air exhaust. The reference airflow meter has a built-in airflow straightener and, according to the manufacturer, no straight section of ductwork is needed upstream of the flow meter to maintain and accuracy of $\pm 0.5 \%$. (No upstream straight duct was provided). Based on our evaluations of this type of flow meter using the Pitot tube traverse method, errors in measuring the flow meter's pressure signal are the largest source of flow rate measurement error. Accounting for the drift in the calibration of our pressure transducer, for reference flow rates exceeding $250 \mathrm{cfm}\left(118 \mathrm{~L} \mathrm{~s}^{-1}\right)$, we estimate that the accuracy of the reference flow rate measurements was approximately $\pm 7 \%$ or better.

Technologies for measuring OA flow can be installed per manufacturers specifications. Turning vanes are installed in the bend of the recirculation ductwork upstream of the location where recirculated and outdoor air mix. Independent control of the OA and recirculation air flow rates can be accomplished using the dampers and variable speed fan. Because the system is sealed to reduce air leakage to a negligible level ${ }^{4}$, the flow of OA into the test system effectively equals the exhaust airflow rate, which is measured with the reference airflow meter. Thus, the accuracy of the OA measurement technology being tested is determined by comparison to the reference airflow meter, and the percentage measurement error (\%error) is calculated from the following equation:

$$
\% \text { error }=100 \%\left(Q_{m t}-Q_{r e f}\right) / Q_{r e f}
$$

where $Q_{m t}$ and $Q_{r e f}$ are the OA flow rates from the measurement technology being evaluated and the reference flow meter, respectively.

\footnotetext{
${ }^{4}$ All joints were carefully caulked and smoke tubes were used to check for leaks.
} 


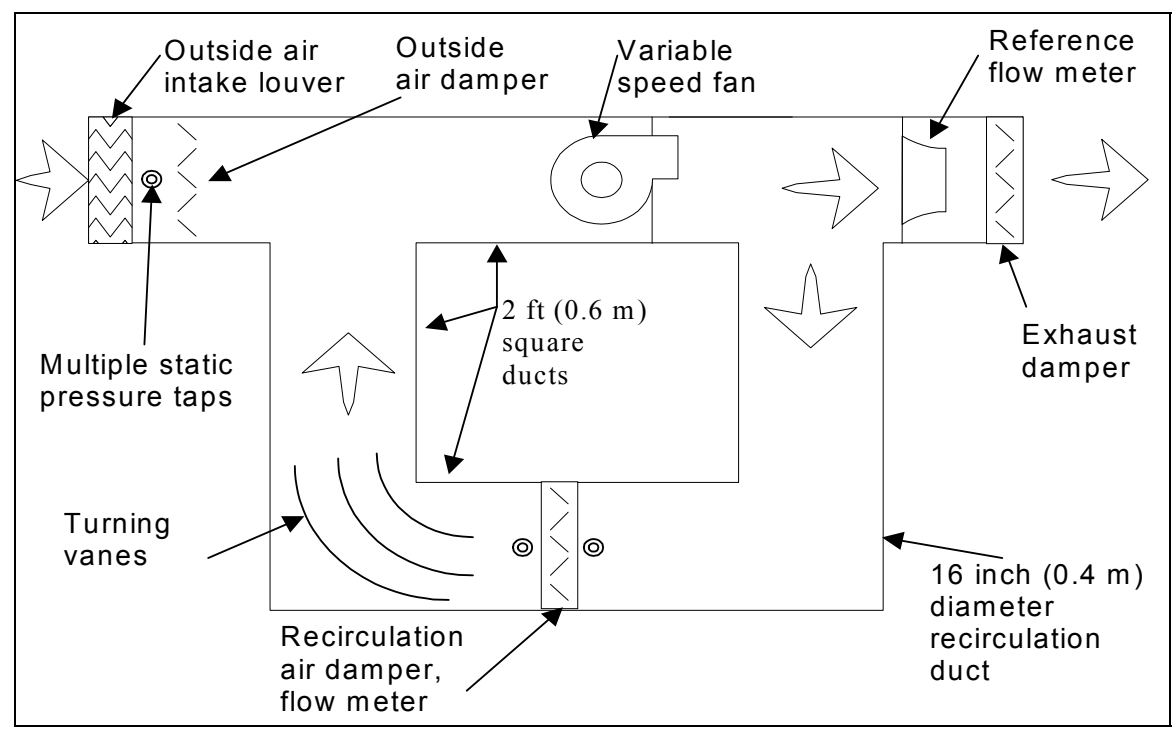

Figure 1. Illustrative diagram of test system

Static pressure taps are installed at a number of locations to enable measurements of pressure drops across the measurement systems. Per specifications in ANSI/ASHRAE standards (ASHRAE 1999a, ASHRAE $1999 \mathrm{~b})$, the taps are 0.07 inch $(1.8 \mathrm{~mm})$ diameter holes in the duct wall with a smooth inner face.

The recirculation flow rate (not used in this paper) is measured with less accuracy based on the pressure drop across an iris-style damper, relying on the manufacturer's calibration of flow versus pressure drop.

The output signals of pressure transducers are logged with a data acquisition system. Instrumentation specifications and our estimates of accuracy during the tests are provided in Table 1. The calibration of the eight-channel pressure transducer system was checked using a micro-manometer that has a micrometer and electrical circuit for precisely measuring the height of the fluid column. A skilled user of the micro-manometer can obtain measurements repeatable within 0.0005 inch water $(0.1 \mathrm{~Pa})$. However, after accounting for instrument drift, the errors in pressure measurements may be as high as $\pm 2 \mathrm{~Pa}$.

Table 1. Instrumentation used with the test system

\begin{tabular}{|c|c|c|c|}
\hline $\begin{array}{l}\text { Parameter } \\
\text { Measured }\end{array}$ & Type of Instrument & Measurement range & $\begin{array}{l}\text { Manufacturer's } \\
\text { Rated Accuracy } \\
\text { [estimated accuracy } \\
\text { in use] }\end{array}$ \\
\hline $\begin{array}{l}\text { Exhaust } \\
\text { (reference) } \\
\text { flow rate }\end{array}$ & $\begin{array}{l}18 \text { " and } 10 " \text { flow meters } \\
\text { flow meters have a flow } \\
\text { straightener and converging } \\
\text { nozzle, with Pitot-static type } \\
\text { sensor centered at outlet of } \\
\text { nozzle }\end{array}$ & $\begin{array}{l}\text { Large } 18 \text { " flow meter: } 690 \text { to } 3700 \\
\text { cfm }\left(0.33 \text { to } 1.75 \mathrm{~m}^{3} \mathrm{~s}^{-1}\right) \text { with } \\
\text { pressure signal of } 0.4 \text { to } 1.2 \text { inch } \\
\text { water }(10 \text { to } 290 \mathrm{~Pa}) \text {. } \\
\text { Small } 10 " \text { flow meter: } 330 \text { to } 1160 \\
\text { cfm }\left(0.16 \text { to } 0.55 \mathrm{~m}^{3} \mathrm{~s}^{-1}\right) \text { with } \\
\text { pressure signal of } 0.1 \text { to } 1.3 \text { inch } \\
\text { water ( } 26 \text { to } 330 \mathrm{~Pa})\end{array}$ & $\begin{array}{l}0.5 \% \text { of reading } \\
{[ \pm 7 \% \text { or better for }} \\
\text { reference flow } \\
\text { exceeding } 250 \mathrm{cfm} \\
\left.\left(0.09 \mathrm{~m}^{3} \mathrm{~s}^{-1}\right)\right]\end{array}$ \\
\hline $\begin{array}{l}\text { Recirculation } \\
\text { flow rate }\end{array}$ & $\begin{array}{l}16 \text { " Iris Damper with } \\
\text { integral differential pressure } \\
\text { flow meter }\end{array}$ & $\begin{array}{l}150 \text { to } 4000 \mathrm{cfm}\left(0.07 \text { to } 1.9 \mathrm{~m}^{3} \mathrm{~s}^{-}\right. \\
\left.{ }^{1}\right) \text { for differential pressure range of } \\
0.1 \text { to } 2.0 \text { inch water }(25 \text { to } 500 \mathrm{~Pa})\end{array}$ & $\pm 7 \%$ of reading \\
\hline $\begin{array}{l}\text { Pressure } \\
\text { difference }\end{array}$ & $\begin{array}{l}\text { Eight channel electronic } \\
\text { differential pressure } \\
\text { transducer }\end{array}$ & \pm 1.6 inch water $( \pm 400 \mathrm{~Pa})$ & $\begin{array}{l}\text { Larger of } \pm 0.001 \text { inch } \\
\text { water }( \pm 0.2 \mathrm{~Pa}) \text { or } \pm \\
1 \% \text { of reading } \\
{[ \pm 2 \mathrm{~Pa} \text { or better }]}\end{array}$ \\
\hline
\end{tabular}


The velocity profile of air entering an OA intake may be affected by winds. Our limited preliminary tests (described subsequently) have indicated that winds can affect the accuracy of OA measurement technologies; however, further work is needed to evaluate practical methods of producing repeatable simulated winds at the outdoor air intake. We have also designed our test systems for optional placement on a building rooftop with real winds.

In practice, OA intakes are located near some surfaces such as rooftops, walls of buildings, or walls used as visual (sometimes called architectural) screens, that may affect the entering velocity profiles and the accuracy of OA flow measurement technologies. In the laboratory, we have used movable flat panels, normally $8 \mathrm{ft}$ by $8 \mathrm{ft}(2.4 \mathrm{~m}$ by $2.4 \mathrm{~m})$, to simulate these surfaces, as illustrated in Figure 2.

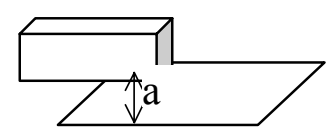

Orientation 1

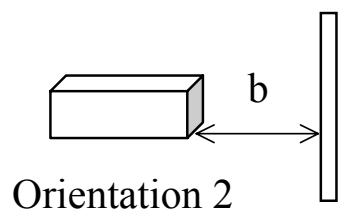

Orientation 2

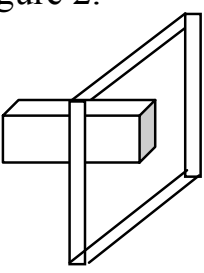

Orientation 3

Figure 2. Orientations of flat panels used to simulate the presence of a rooftop (orientation 1), visual screen (orientation 2) or building wall (orientation 3) near the OA intake. $a=1 \mathrm{ft}(0.3 \mathrm{~m})$ and $\mathrm{b} \geq 0.33 \mathrm{ft}$ $(0.1 \mathrm{~m})$. The grey shaded surface denotes the OA intake. In orientation 3 , the OA intake was located in the same plane as the flat panel, simulating an OA intake flush with an exterior wall of a building.

\section{Test protocol}

The protocol for evaluating measurement technologies is still being developed, but is rather straightforward. By adjusting dampers and fan speeds, OA flow rates were varied over the desired range. Recirculation air flow rates were adjusted so that the percentage of outdoor air (\%OA), [i.e., outdoor air flow rate divided by outdoor plus recirculation flow rate, expressed as a percentage] ranged from $10 \%$ to $100 \%$. To assess the effects of surfaces (walls or a rooftop) near the outdoor air intake, movable flat panels were placed in the three orientations shown within Figure 2, or removed. For some tests, we varied the degree of opening of the OA damper located just downstream of the intake louver. Data were collected with the damper open approximately $100 \%, 50 \%$ and $25 \%$, based on the angle of the shaft that normally connects the damper system to a damper motor.

Using a fan and flow straightener to simulate steady winds at the OA intake, we performed a very limited preliminary investigation to determine if winds could affect the accuracy of measurements when there were no simulated surfaces or visual screens near the OA intake. The simulated winds, with a speed range of 2 to $7 \mathrm{mph}\left(1\right.$ to $\left.3 \mathrm{~m} \mathrm{~s}^{-1}\right)$, were oriented directly into the face of the OA inlet and also at 45 degree angles from each side of the OA inlet.

\section{$\underline{\text { Measurement technologies }}$}

This report summarizes results of our evaluations of three OA measurement technologies, primarily under conditions without winds at the OA intake. Measurement technology number 1 (MT1), illustrated in Figure 3, integrates a set of closely spaced $(1.5$ inch $[3.8 \mathrm{~cm}])$ vertical louvers with a set of downstream airflow sensing blades that extend over the height of the louver system and that are centered between adjacent blades of the louver. The manufacturer provides a calibration curve in terms of average air velocity through the free-area of the louver system versus pressure signal from the airflow sensing blades. The airflow sensing blades appear to be designed to provide a pressure signal proportional to the average velocity along a vertical path centered between adjacent louvers. Compared to many louver systems, the 
MT1 louver system also has a relatively high recommended maximum free area velocity which helps to maintain a measurable pressure signal. The shape of the airflow-sensing blade also yields a larger pressure signal than a standard Pitot-static tube.

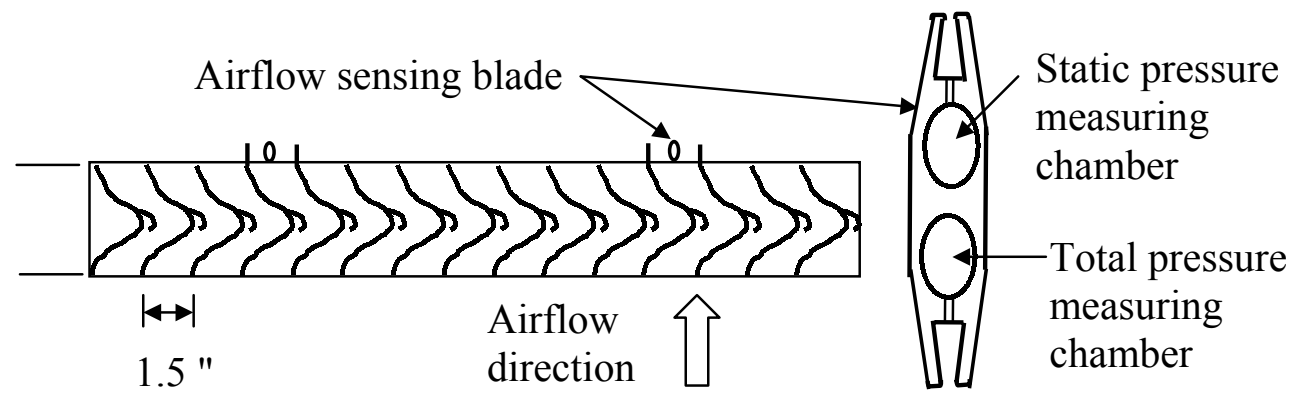

Figure 3. Illustration of outdoor airflow measurement technology number 1 (MT1). Top views of cross section of the louvers and airflow sensing blades are shown. The airflow sensing blades extend vertically nearly the full height of the louver system.

The tests of MT1 were conducted with a nominal $2 \mathrm{ft}$ by $2 \mathrm{ft}(0.6 \mathrm{~m}$ by $0.6 \mathrm{~m})$ louver system [denoted louver no. 1 or L1] with two downstream sensing blades. The manufacturer's-reported free area of the louver system is $1.24 \mathrm{ft}^{2}\left(0.12 \mathrm{~m}^{2}\right)$, or $31 \%$ of the nominal face area. The manufacturer's minimum "velocity requirement" for MT1 was $345 \mathrm{fpm}\left(1.8 \mathrm{~m} \mathrm{~s}^{-1}\right)$ in the free area of the louver. The corresponding OA flow is $430 \mathrm{cfm}\left(0.20 \mathrm{~m}^{3} \mathrm{~s}^{-1}\right)$. The maximum recommended ${ }^{5}$ air velocity in the free area of the same louver without the airflow blades is $1856 \mathrm{fpm}(9.4 \mathrm{~m} / \mathrm{s})$, with a corresponding maximum flow rate of $2300 \mathrm{cfm}\left(1.1 \mathrm{~m}^{3} \mathrm{~s}^{-1}\right)$. Manufacturers data indicate that the pressure drop across the louver system (without a bird screen) ranges nonlinearly from $0.01 \mathrm{inch}$ water $(2.5 \mathrm{~Pa})$ with an air velocity through the free area of $470 \mathrm{fpm}\left(2.4 \mathrm{~m} \mathrm{~s}^{-1}\right)$ to 3 inch water $(747 \mathrm{~Pa})$ with a velocity of $7300 \mathrm{fpm}\left(37 \mathrm{~m} \mathrm{~s}^{-1}\right)$. MT1 was installed with 27.5 inch $(70 \mathrm{~cm})$ of straight duct located between the downstream edge of the louver and the upstream edge of the fully open OA damper

Measurement Technology number 2 (MT2) illustrated in Figure 4 uses thermal dispersion anemometry sensors installed at the periphery of multiple holes in one or more tubes (called probes) that are inserted perpendicular to the flowing air. A self-heated thermistor and unheated thermistor are located $180^{\circ}$ apart at the periphery of each hole, and the airflow through the hole affects the extent to which the unheated thermister records a temperature above ambient, leading to a velocity signal. Associated electronics power the sensors and average the signal from multiple sensors, yielding an average velocity. Based on manufacturers specifications, the sensors are temperature compensated between $-20{ }^{\circ} \mathrm{F}$ and $160{ }^{\circ} \mathrm{F}\left(-29^{\circ} \mathrm{C}\right.$ and $\left.71{ }^{\circ} \mathrm{C}\right)$ and water resistant and never require recalibration. The calibrated velocity range is 0 to 5000 fpm $\left(0\right.$ to $\left.25 \mathrm{~m} \mathrm{~s}^{-1}\right)$ and the manufacturers rated installed airflow accuracy is $2 \%$ to $3 \%$ of the reading.
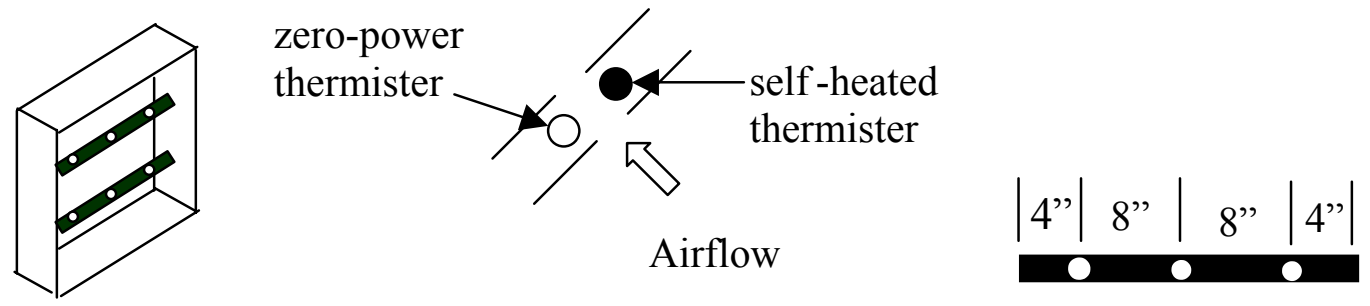

Figure 4. Illustration of measurement technology \#2. The left side of figure shows two probes in a section of duct that would typically be downstream of outdoor air louvers and upstream of outdoor air

${ }^{5}$ The velocity at which the results of a moisture entrainment test meet certain criteria 
dampers. The central diagram shows a detail of a sensor within a probe. The right diagram shows the locations of sensors in a probe.

In the experiments with a nominal $2 \mathrm{ft}$ by $2 \mathrm{ft}$ louver, per the manufacturers recommendations we used two probes with three sensors per probe. In this type of installation, the manufacturer recommends a minimum 14 inch $(0.36 \mathrm{~m})$ undisturbed airflow path between the louver and damper with installation of the sensors 12 inch $(0.30 \mathrm{~m})$ downstream of the louvers and as close as 2 in $(5 \mathrm{~cm})$ upstream of the OA damper. When a longer undisturbed airflow path is available, the manufacturer recommends installation of probes two-thirds of the distance downstream of upstream component (louver). In our tests, the distance between the downstream edge of the louver and upstream edge of the fully open damper was 23 inch $(58 \mathrm{~cm})$. Probes were located 15.5 inch $(39 \mathrm{~cm})$ downstream of downstream edge of the louver and 7.5 inch $(19 \mathrm{~cm})$ upstream of upstream edge of the fully open damper, and, in some tests, at other locations. Probes were installed one-third and two-thirds of the distance across the duct, horizontally in some tests and vertically in other tests, and installed at other locations to determine how location affected accuracy. The velocity displayed by MT2 was a constant multiple of the MT2 voltage output signal. To calculate the air flow rate, we recorded the output voltage, calculated the velocity (which was more convenient than manually reading the displayed velocity), and them multiplied this velocity by the $4 \mathrm{ft}^{2}$ $\left(0.37 \mathrm{~m}^{2}\right)$ cross sectional area of the duct located between the louvers and OA damper.

Measurement technology number 3 (MT3) uses special static pressure taps at the outdoor face of the OA inlet and downstream of the OA louver to sense the pressure drop across the louver. The outdoor pressure tap, mounted on the inlet face of the louver system is designed to provide a pressure signal unaffected by wind direction. The pressure tap placed downstream of the louver, called an "inlet airflow sensor" is a 0.5 inch $(1.3 \mathrm{~cm})$ diameter 5 inch $(13 \mathrm{~cm})$ long cylinder with a 0.8 inch $(2 \mathrm{~cm})$ long sintered metal end that is inserted through a duct wall into the airstream. We presume that this tap is designed to provide a reliable measure of static pressure in the turbulent airstream located downstream of a louver. The full MT3 system comes with a pressure transducer, temperature sensor to enable control for air density, electronics, and a digital display. The system is designed for OA velocity ranges of either 150 to $600 \mathrm{fpm}$ ( 0.8 to $3.0 \mathrm{~m} \mathrm{~s}^{-1}$ ) or 250 to $1000 \mathrm{fpm}\left(1.3\right.$ to $\left.5.1 \mathrm{~m} \mathrm{~s}^{-1}\right)$ and has a rated accuracy of $\pm 5 \%$ of the reading. The relationship of measured pressure drop to OA flow rate will vary with the design of the louver and must therefore be determined via a factory or field-based determination of this relationship. Because we performed tests indoors without wind, we did not mount the outdoor pressure tap on the face of the louver, where it would block a portion of the air flow. We also did not use the manufacturer's electronics or pressure sensor -- we used our research grade pressure transducer to measure the pressure difference. Thus, our tests only determined whether the OA flow rate could be determined by measuring the pressure difference across an OA inlet louver using the "inlet airflow sensor" as the pressure tap downstream of the louver. Because field based measurements of OA flow- pressure drop relationship may be impractical, we determined air flow rates from the pressure drop -velocity data provided by the louver manufacturers. We installed the "inlet airflow sensor" through the duct side wall at a location 25 inch (64 $\mathrm{cm})$ downstream from downstream edge the louver of MT1 and 15.5 inch $(39 \mathrm{~cm})$ downstream of the downstream edge louver 2 , described below.

For tests of MT2 and MT3, we employed a louver system lower in cost than the louver in MT1, called louver 2 (L2), that is illustrated in Figure 5.

In addition to testing the three measurement technologies, a handheld thermal hot wire anemometer system was used to develop maps of air speed downstream of louvers. Air speed measurements were made at locations spaced 2 inch $(5 \mathrm{~cm})$ both horizontally and vertically. The anemometer extended only 18 inch $(46 \mathrm{~cm})$ horizontally into the duct; thus, data were not available at locations 2 and 4 inch (5 and $10 \mathrm{~cm}$ ) from one side wall of the duct). 


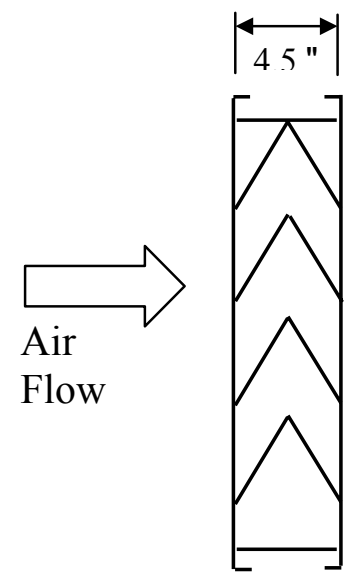

Figure 5. Illustration of cross section of louver 2.

\section{Results}

\section{Measurement Technology 1}

Figure 6 shows the \%error of MT1 plotted versus the reference OA flow rate. The figure includes results of tests with a range of $\% \mathrm{OA}$ and with a range of $\mathrm{OA}$ damper positions. The measured pressure signal from the airflow sensor blades of MT1 is also plotted. With our research-grade pressure transducer used to measure this pressure difference, MT1 is accurate within approximately $\pm 20 \%$ for outdoor air flow rates exceeding approximately $250 \mathrm{cfm}\left(0.12 \mathrm{~m}^{3} \mathrm{~s}^{-1}\right)$. In actual applications, the pressure transducer normally used in conjunction with MT1 will be less accurate (and also less expensive) than our researchgrade pressure transducer. Therefore, for four OA flow rates, Figure 4 includes sets of error bars illustrating the expected range of accuracy of MT1 with errors in differential pressure measurement of \pm 0.004 and \pm 0.012 inch water $( \pm 1 \mathrm{~Pa}$ and $\pm 3 \mathrm{~Pa}$ ), which

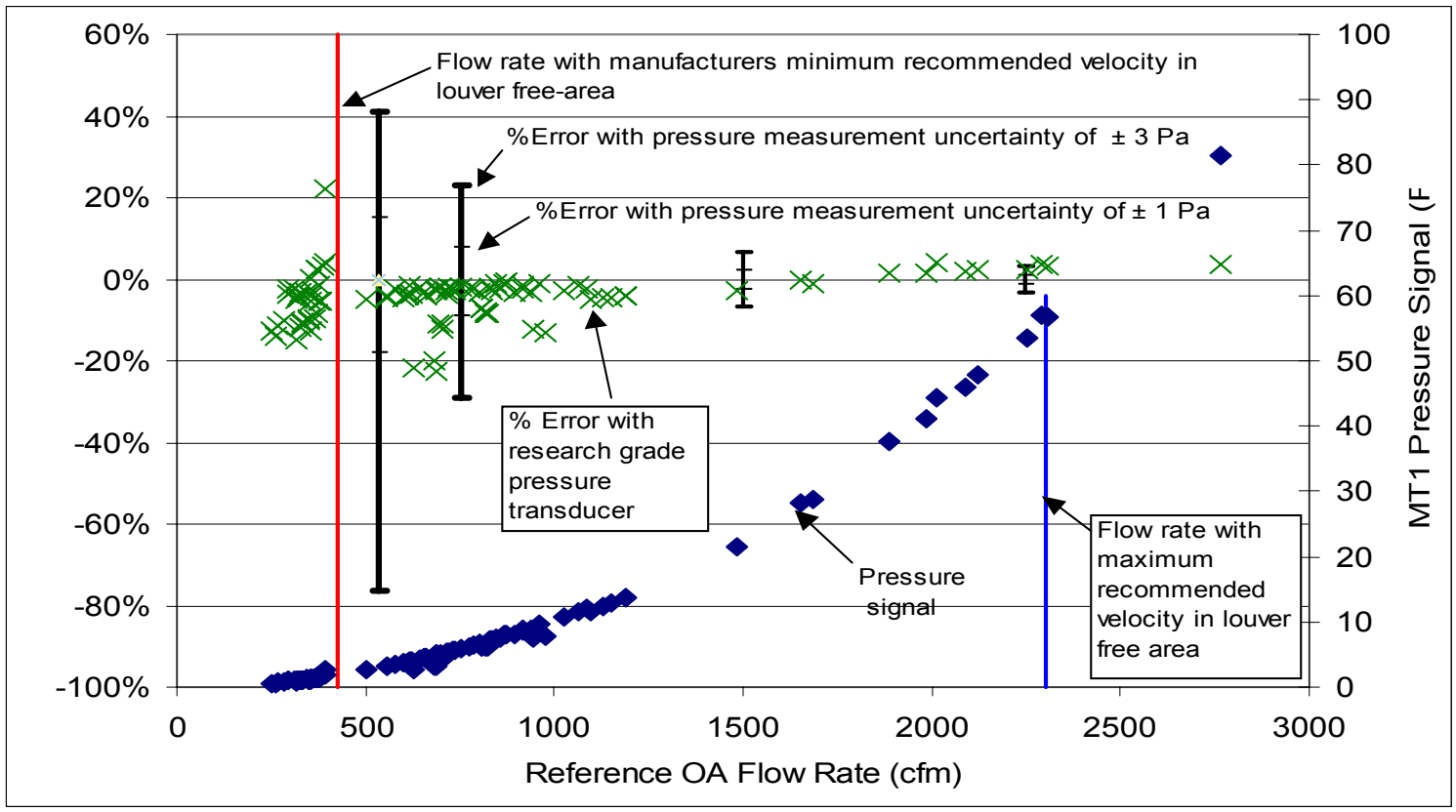

Figure 6. Accuracy and pressure drop of MT1 versus flow rate. 
are consider more typical of the errors that occur with the electronic pressure transducers commonly used in field settings. With an error in pressure measurement of $\pm 0.012 \mathrm{~Pa}( \pm 3 \mathrm{~Pa})$, the corresponding error in OA flow rate exceeds $25 \%$ with a flow rate of $750 \mathrm{cfm}\left(350 \mathrm{~L} \mathrm{~s}^{-1}\right)$, which is almost $175 \%$ of the manufacturers recommended minimum flow rate. If pressure measurement errors can be limited to \pm 0.004 inch water $( \pm 1 \mathrm{~Pa})$, the maximum error in outdoor air flow rate measurement is about $30 \%$ at the manufacturers minimum recommended flow rate.

Placement of wall surfaces near the outdoor air intake in the three configurations illustrated in Figure 2 had no discernable impact on the accuracy of MT1 (data not shown). The exception was a reduced accuracy in configuration 2, emulating a visual screen, when dimension " a" was $0.33 \mathrm{ft}(0.1 \mathrm{~m})$ or less. However, in practice visual screens will normally located be at least $3 \mathrm{ft}(1 \mathrm{~m})$ from the OA inlet to enable access.

Based on a more detailed examination of the test data Fisk et al. (2002), the accuracy of MT1 appeared to be nearly independent of both \% OA (i.e., the rate of air recirculation) and the degree of opening of the OA damper.

The effects of directing 2 to $7 \mathrm{mph}\left(0.9\right.$ to $\left.3 \mathrm{~m} \mathrm{~s}^{-1}\right)$ simulated winds at the OA intake were variable. When the reference OA flow was $900 \mathrm{cfm}\left(0.42 \mathrm{~m}^{3} \mathrm{~s}^{-1}\right)$ with a corresponding average velocity of $720 \mathrm{fpm}(3.7$ $\mathrm{m} \mathrm{s}^{-1}$ ) in the free area of the louver system, the simulated winds had a discernable but unimportant (few percent) impact on measurement accuracy. With a reference OA flow of $400 \mathrm{cfm}\left(0.19 \mathrm{~m}^{3} \mathrm{~s}^{-1}\right)$, winds at a 45 degree angle increased measurement errors by up to 25 percentage points. Wind from the left side of the OA intake, when viewed from the top, caused the largest error. From inspection of the louver geometry depicted in Figure 3, winds from right and left and right sides of the louver system would be expected to differentially impact velocities within the louver system.

\section{Measurement Technology 2}

Figure 7 shows the \%error of MT2 plotted versus the reference OA flow rate. The different sections of the figure illustrate the effects of probe installation location, presence of OA dampers $7.5 \mathrm{inch}(19 \mathrm{~cm})$ downstream of the probes, air recirculation, and probe orientation (horizontal and vertical). From an examination of the figures, it is apparent that measurement errors span a very large range from $-60 \%$ to $+190 \%$. Errors increase as the flow rate falls below approximately $400 \mathrm{cfm}\left(0.19 \mathrm{~m}^{3} \mathrm{~s}^{-1}\right)$, corresponding to an average air velocity in the duct cross section of $100 \mathrm{fpm}\left(0.5 \mathrm{~m} \mathrm{~s}^{-1}\right)$. Errors were much larger, always exceeding $+50 \%$, and always positive (probe reading too high) with the vertical probe orientation, while the probe reading was generally lower than the reference flow rate with a horizontal probe location. With a horizontal probe orientation, the absence of an outdoor air damper downstream of the probes was associated with a reduction in error from the $-60 \%$ to $-30 \%$ range (with damper), to the $-20 \%$ to $0 \%$ range (without damper). With a vertical probe orientation, the absence of a downstream OA damper was associated with a reduction in error from approximately $+120 \%$ to $+70 \%$. We did not determine if increases in the distance between the probes to the OA dampers would reduce errors. With the horizontal probe orientation, moving both probes 2 inch upward from their normal locations (one third of the duct dimension from top and bottom walls) appeared to reduce errors by roughly $20 \%$. To our surprise, errors were further reduced to the $\pm 20 \%$ range when the probes were placed very close to the top and bottom walls of the duct. 


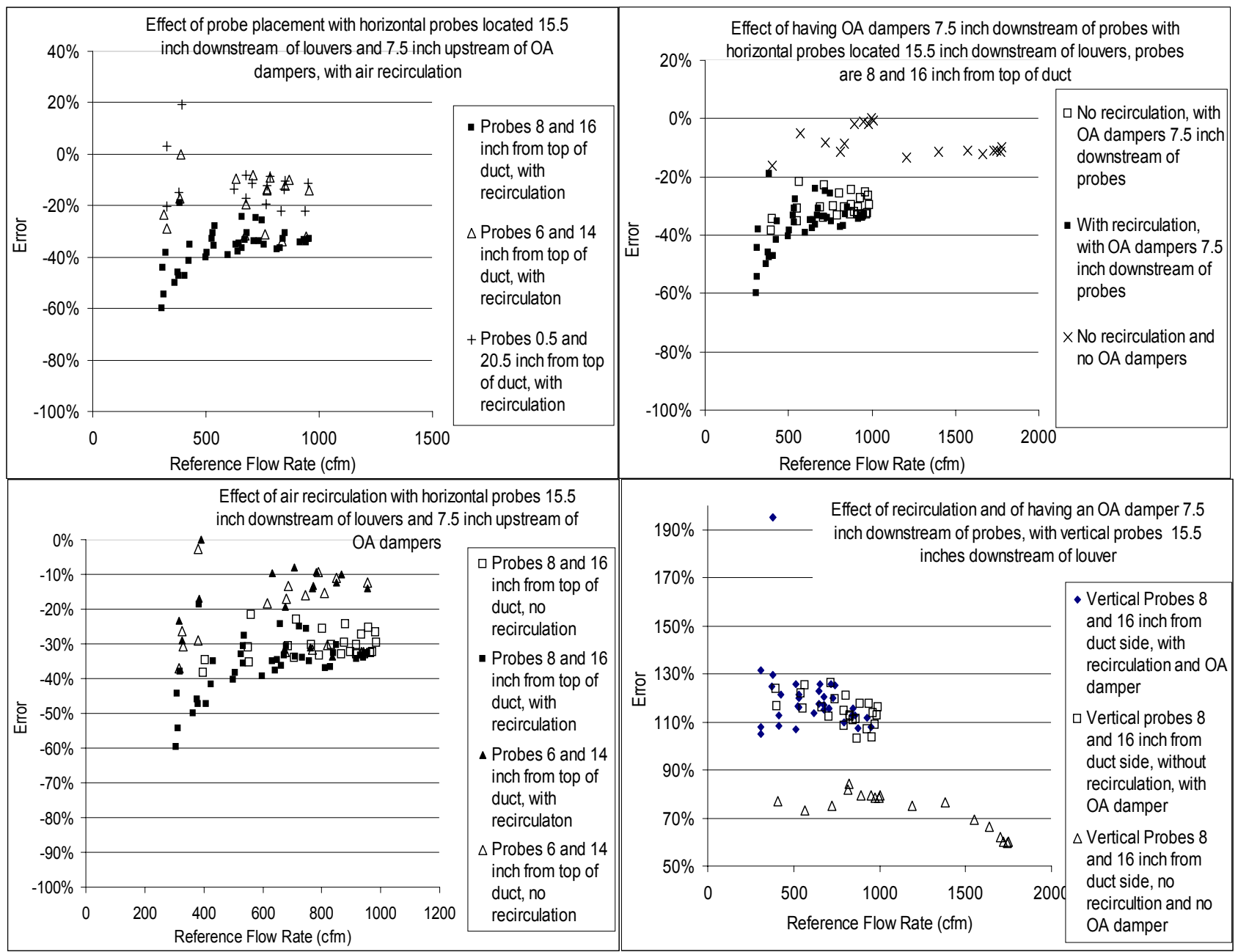

Figure 7. Results of tests of MT2

Figure 8 provides an example of the velocity traverse performed downstream of L2, used upstream of MT2. The profile is highly asymmetrical in the vertical dimension, with particularly high air speeds near the top and bottom of the duct, but the profile is nearly symmetrical in the horizontal direction. The highest velocities near the top of the duct are difficult to explain ${ }^{6}$ because the top of the OA inlet louver blocks the OA flow.

By assuming horizontal symmetry, the two right most columns of air speeds have been added to Figure 8 . The outlined boxes of Figure 8 contain the air speeds measured at locations 1 inch $(2.5 \mathrm{~cm})$ above and below the sensors of MT2, when the probes were installed vertically. If one averages the air speeds measured 1 inch $(2.5 \mathrm{~cm})$ below the MT2 sensors and multiplies the resulting average speed by the duct cross sectional area, the resulting predicted air flow rate is $11 \%$ smaller than the reference flow rate;

${ }^{6}$ One potential explanation is that air flow backwards through the OA damper near the top of the duct. However, despite use of the same OA damper and recirculation rates, these high velocities near the top of the duct were largely absent in traverses downstream of $L 1$ and completely absent downstream of an airflow straightener located in place of the louver. 
however, using the airspeeds measured 1 inch $(2.5 \mathrm{~cm})$ higher in the duct yields an air flow rate that exceeds the reference flow rate by $61 \%$. Calculations using air speeds measured at the location of MT2 sensors, with the probes installed horizontally, resulted in predicted flow rates that are $24 \%$ and $39 \%$ less than the reference flow rate. Similar large errors were found with higher and lower reference flow rates through L2. When the same calculations were performed using data from velocity traverses downstream of L1, the errors (deviation from reference flow rate) ranged from $-20 \%$ to $+160 \%$. These data show very clearly that basing flow rates on six measurements of air speeds downstream of a louver can lead to large errors.

\begin{tabular}{|c|c|c|c|c|c|c|c|c|c|c|c|c|}
\hline & \multicolumn{12}{|c|}{ Horizontal distance from top left side of duct (inch) } \\
\hline & $0 "$ & 2" & $4 "$ & 6" & 8" & $10 "$ & $12 "$ & $14 "$ & $16 "$ & $18 ”$ & $20 "$ & $22 "$ \\
\hline \multirow{12}{*}{$\begin{array}{l}\text { Vertical } \\
\text { distance } \\
\text { from top } \\
\text { of duct } \\
\text { (inch) }\end{array}$} & $1 "$ & 18.4 & 17.2 & 17.2 & 17.7 & 17.6 & 17.1 & 16.7 & 17.4 & 13.7 & 17.2 & 18.4 \\
\hline & $3 "$ & 11.2 & 12.5 & 12.6 & 12.5 & 10.1 & 10.0 & 9.6 & 7.9 & 9.5 & 12.5 & 11.2 \\
\hline & $5 "$ & 6.4 & 3.8 & 6.1 & 4.4 & 3.0 & 3.0 & 3.6 & 2.9 & 1.8 & 3.8 & 6.4 \\
\hline & 7" & 5.0 & 2.8 & 2.8 & 2.0 & 2.0 & 2.0 & 1.9 & 1.6 & 2.1 & 2.8 & 5.0 \\
\hline & 9" & 5.0 & 1.7 & 1.5 & 1.6 & 1.6 & 1.7 & 1.7 & 1.7 & 1.8 & 1.7 & 5.0 \\
\hline & $11^{\prime \prime}$ & 3.3 & 2.1 & 1.7 & 1.6 & 1.6 & 1.6 & 1.6 & 1.6 & 1.6 & 2.1 & 3.3 \\
\hline & $13^{\prime \prime}$ & 3.1 & 1.9 & 1.9 & 1.8 & 1.8 & 1.6 & 1.6 & 1.7 & 1.7 & 1.9 & 3.1 \\
\hline & $15^{\prime \prime}$ & 2.6 & 1.8 & 1.7 & 1.7 & 1.7 & 1.6 & 1.6 & 1.5 & 1.9 & 1.8 & 2.6 \\
\hline & $17^{\prime \prime}$ & 1.8 & 1.7 & 1.7 & 1.8 & 1.8 & 1.8 & 1.7 & 1.8 & 2.0 & 1.7 & 1.8 \\
\hline & $19 "$ & 1.9 & 1.8 & 1.7 & 1.7 & 1.7 & 1.7 & 2.2 & 1.8 & 1.9 & 1.8 & 1.9 \\
\hline & $21 "$ & 2.1 & 1.8 & 2.2 & 2.2 & 2.2 & 3.2 & 2.8 & 2.0 & 1.8 & 1.8 & 2.1 \\
\hline & $23 "$ & 3.2 & 3.2 & 4.7 & 5.2 & 4.9 & 5.4 & 5.3 & 4.8 & 3.3 & 3.2 & 3.2 \\
\hline
\end{tabular}

Figure 8. Example velocity profile from measurements 15.5 inch $(39 \mathrm{~cm})$ downstream of louver 2, with air speeds in $\mathrm{ft} \mathrm{s}^{-1}$. The two right columns of velocities were not measured -- they were based on an assumption of horizontal symmetry.

\section{Measurement Technology 3}

Figure 9 shows how the reference value of OA flow rate varies with the pressure drops measured across L1 and L2, when the inlet airflow sensor of MT3 was used to sense the static pressure downstream of the louvers. The inlet airflow sensor was installed at two locations. The first location was $7.5 \mathrm{inch}(19 \mathrm{~cm})$ downstream of the downstream edge of L1 [4.5 inch $(11.4 \mathrm{~cm})$ downstream of L2], 12 inch $(30.5 \mathrm{~cm})$ from the top of the duct, inserted through a vertical duct wall. The second location was 20 inch $(51 \mathrm{~cm})$ further downstream from the louvers and 8 inch $(20 \mathrm{~cm})$ from the top of the duct, inserted through he same duct wall. For comparison, the figure shows curves of flow rate versus pressure drop based on data from the manufacturer of the louvers, and the flow versus average pressure drop from the three static pressure taps located on the duct top wall and two side walls. It is evident that the pressure drop measured with the inlet airflow sensor of MT3 varies smoothly with OA flow rate and has nearly the same value at the two installed locations. These results indicate that the OA flow sensor could be used for a reliable determination of $\mathrm{OA}$ flow rate if the pressure drop were accurately measured and a calibration curve of flow rate versus pressure drop were known. If a single louver and OA damper were used in an HVAC system with an economizer, the measured pressure drops would be only 0.01 to 0.02 inch water (2 to $4 \mathrm{~Pa}$ ) with expected minimum OA flow rates. With these low OA flowrates, the errors in determination of $\mathrm{OA}$ flow rate could easily exceed $50 \%$ unless a very accurate pressure transducer was used to make the pressure measurements. 
If the manufacturer's data were used to predict the OA flow rate, the resulting predicted flow rate would be $25 \%$ and $33 \%$ higher than the reference OA flow rate for L1 and L2, respectively. The average of static pressure drops measured using the three wall-mounted static pressure taps better matched the manufacturer's data, but the agreement may be fortuitous because the pressure varied substantially among the three locations.

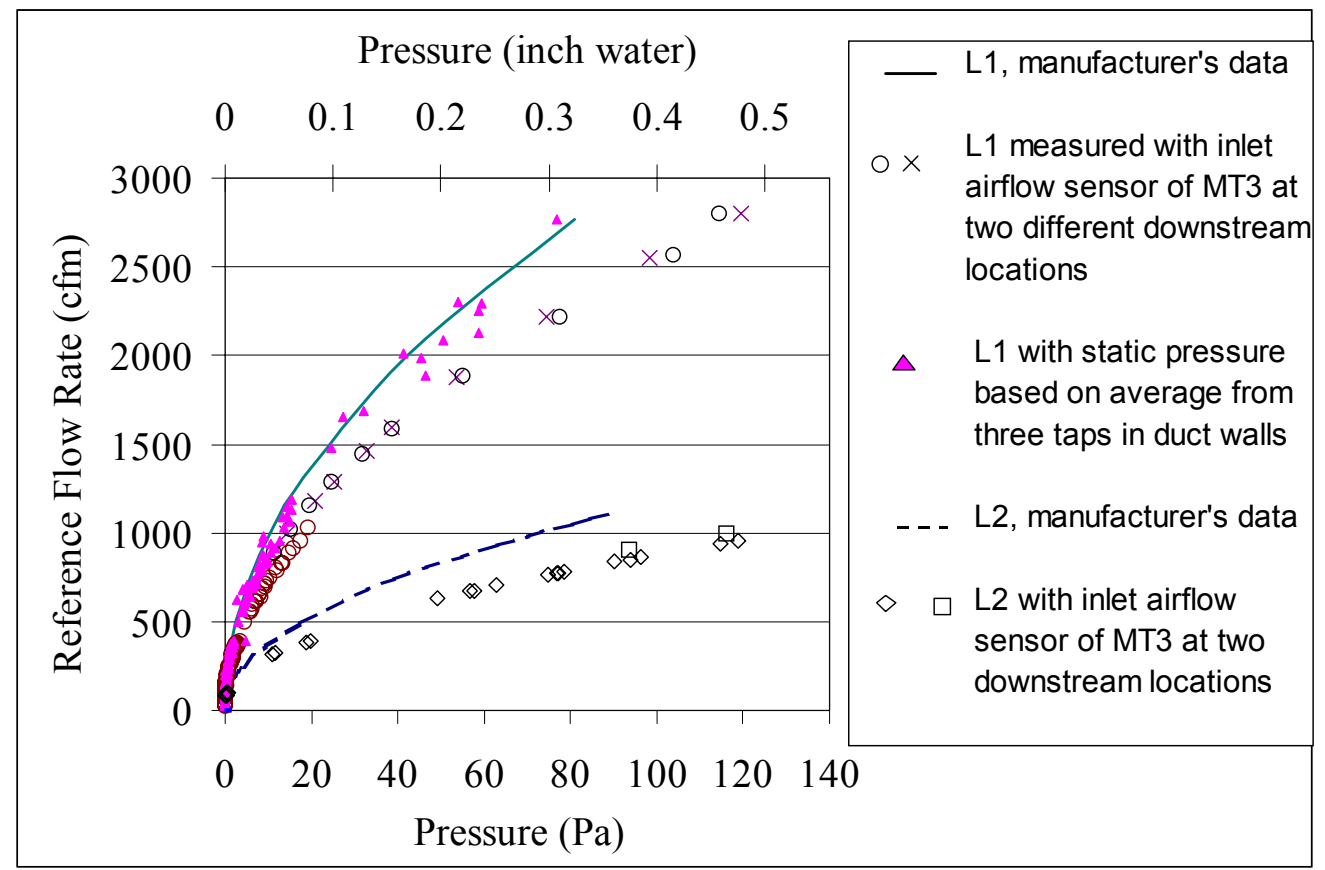

Figure 9. Relationship of reference flow with pressure drop across L1 and L2 using the inlet airflow sensor of MT3 downstream of the louvers.

\section{Discussion}

Testing methods

The test system and protocol developed for this project provided a convenient and accurate method of evaluating the accuracy of the measurement technologies under conditions without wind. Individual data points could be obtained rapidly (e.g., within one minute) after flow rates were adjusted to obtain the desired conditions. If large numbers of tests were required, a computer control system could be developed to automatically adjust damper positions and fan speeds. Replacing the large reference flow meter with the smaller reference flow meter (or vice versa) required approximately 15 minutes of labor. Removing and replacing the OA flow measurement technology in the experimental system may require up to several hours of labor, depending upon the technology. Further work is necessary to evaluate hardware and protocols for assessing the influence of winds on measurement system accuracy. In addition, to confirm the reliability of data obtained with simulated winds we believe that limited testing should be performed with the system exposed to real winds.

\section{Performance of Measurement Technologies}

We have not surveyed potential users of OA measurement technologies to assess their accuracy requirements. However, considering the complete lack of an $\mathrm{OA}$ air flow rate measurement technology in most buildings and the imprecise knowledge of the relationship of OA ventilation rates with health, we anticipate that systems with an accuracy on the order of $\pm 20 \%$ will be considered valuable by users. 
The performance of MT1 under conditions without wind was encouraging. Using a research grade pressure transducer, the accuracy of the OA flow rate measurement was approximately $\pm 20 \%$ or better within the manufacturer's recommended range of OA flow rates of 430 to $2300 \mathrm{cfm}\left(0.20\right.$ to $\left.1.1 \mathrm{~m}^{3} \mathrm{~s}^{-1}\right)$. However, with pressure measurement accuracy typical of the sensors used in actual buildings, the errors in measurement of OA flow rates become very large even with flow rates well above the manufacturers recommended minimum. We envision two options for maintaining acceptable accuracy. The first option is to use a pressure transducer that is more accurate than those typically used and to calibrate the transducer frequently to maintain errors in differential pressure measurement within \pm 0.004 inch water $( \pm$ $1 \mathrm{~Pa})$. The second option is to divide the OA inlet into two parallel sections, each with an independent louver and damper. When rates of outdoor air supply are at or near minimum, one set of dampers would be fully closed to maintain inlet velocities in the other louver-damper system sufficiently high for accurate measurements of OA flow. Increased costs and control complexity are drawbacks to both options. Use of MT1 would not be expected to significantly increase airstream pressure drops in the OA inlet of an HVAC system, as the pressure drop through MT1 is not atypical of the pressure drop through normal louver systems. Thus, MT1 should not noticeably increase fan energy use. The performance of MT1 under conditions with winds remains to be determined. Also, the cost of MT1 could be a barrier to widespread adoption. We paid U.S. $\$ 800$ for the $2 \mathrm{ft}$ by $2 \mathrm{ft}$ louver system with integral airflow blades, without a pressure transducer. For comparison, the cost of L2 was \$200.

In our tests, the air flow rates determined with MT2 (relying on the factory-supplied relationship between output voltage and air speed) often differed by more than $50 \%$ from the reference air flow rate. The probe installation location, installation orientation, and presence of a downstream OA damper all affected accuracy. The analyses of data from velocity traverses downstream of both L1 and L2 illustrate that air speeds at these locations can vary a great deal spatially; hence, it will be very difficult to accurately measure OA flow rates by placing a practical number of velocity sensors in a section of ductwork downstream of a louver. The data do suggest the errors of MT2 could be substantially reduced via a fieldbased calibration. In some HVAC systems, such a calibration may be practical, but is normally very difficult to perform an accurate calibration in the field. Our tests of MT2 were performed using a single louver system, and better accuracy might be obtained with other types of upstream louvers or other probe locations.

The test results suggest that OA flow rate may be determined with reasonable accuracy by measuring the static pressure drop across the louver and applying a calibration curve. The inlet airflow sensor of MT3 yielded a smooth curve of pressure versus flow rate and the measured pressure drop was very similar at two different probe installation locations. Thus, this relatively simple approach appears promising. However, two limitations were identified in our tests. First, in HVAC systems with OA economizers and a single OA louver and damper, the pressure drops will be small and difficult to measure accurately at minimum OA flow rates. This limitation could be overcome using a separate OA louver and damper system for minimum $\mathrm{OA}$, or by using a very accurate pressure transducer and calibrating the transducer frequently. The second limitation identified is that reliance on the manufacturer's pressure-flow relationship for the louvers resulted in 25-33\% errors, implying that one needs a field-based calibration curve if greater accuracy is desuired. As discussed previously, field-based calibrations may be impractical. To overcome this limitation, a manufacturer could provide a factory-calibrated louver system integrated with a short section of downstream ductwork that contains one or more static pressure taps, such as the inlet airflow sensors of MT3. Tests with additional static pressure tap locations, additional louvers, and under conditions with wind are needed to more fully evaluate this promising approach for measuring OA flow rates. 


\section{Conclusions}

The test system and protocol developed for this project provides a convenient and accurate method of evaluating the accuracy of technologies for measuring outdoor airflows into air handling systems. Further research is needed to develop systems and protocols for assessing the influence of winds on measurement accuracy.

MT1 can provide a reasonably accurate measurement of OA flow rate over a broad flow range, under conditions without wind. The measurement of $\mathrm{OA}$ flow rate was accomplished with minimal increase in airflow resistance. In HVAC systems with an OA economizer, accurate measurements of minimum OA flow rates require a separate louver and damper system for minimum OA or a very accurate and frequently calibrated pressure transducer.

The tests of MT2 indicate that that large (e.g., 100\%) errors in measurement of OA flow rates may occur with some probe installation locations, unless an accurate calibration curve was developed in the field. Developing these calibration curves in field settings may be impractical because of the difficulty in measuring OA flow rates. The non-uniform velocities downstream of louvers make it very difficult to accurately determine OA flow rates from a modest number of measurements of air speed downstream of louvers.

The tests indicate that OA flow rate may be determined with good accuracy by measuring the static pressure drop across the louver, using the inlet airflow sensor of MT3 or presumably some other type of static pressure tap. As with MT1, in HVAC systems with an OA economizer, accurate measurements of

minimum OA flow rates require a separate louver and damper system for minimum OA or a very accurate frequently-calibrated pressure transducer. When we relied on the louver manufacturer's pressure drop data, the errors in OA flow rates were $25 \%$ to $33 \%$. Therefore, a field-based calibration curve is necessary if $\pm 20 \%$ accuracy is desired, at least with the two louvers used in our tests. Again we note that it may be impractical to develop accurate calibration curves in field settings. However, it should be possible to provide factory-calibrated louver systems with integral upstream and downstream static pressure taps, making field-based calibrations unnecessary.

Finally, we note that tests with real or simulated winds are needed to further evaluate these measurement technologies.

\section{Acknowledgements}

This work was supported by the assistant Secretary for Energy Efficiency and Renewable Energy, Building Technologies Program of the U.S. Department of Energy under contract DE-AC03-76SF00098. The authors thank Steve Taylor and Peng Xu for their reviews of a draft of this document.

\section{References}

ASHRAE (2001) ANSI/ASHRAE Standard 62-1999 - Ventilation for acceptable indoor air quality. American Society of Heating, Refrigerating, and Air Conditioning Engineers, Inc. Atlanta, GA ASHRAE (1999a) ANSI/ASHRAE Standard 120-1999 (1999) Method of testing to determine flow resistance of hvac ducts and fittings. ASHRAE, Atlanta, GA

ASHRAE (1999b)ANSI/ASHRAE 51-1999 (1999) Laboratory methods of testing fans for aerodynamic performance rating. ASHRAE, Atlanta, GA 
Emmerich SJ and Persily AK (1998) Energy impacts of infiltration and ventilation in U.S. office buildings using miultizone airflow simultion. Proceedings of IAQ and Energy 98, pp. 191-206, ASHRAE, Atlanta, GA.

Fisk WJ, Faulkner D, Sullivan DP, and Delp W. (2002) Measuring rates of outdoor airflow into HVAC systems. Lawrence Berkeley National Laboratory Report, LBNL-51583. Berkeley, CA

Howell, RH and Sauer HJ (1987) Velocity variation effects on a rotating vane anemometer at coil faces. ASHRAE Transactions 93(2): 200-210

Kettler JP (1995) Minimum ventilation control for VAV systems: fan tracking versus workable solutions. ASHRAE Transactions 101(2): 625-630

Krarti, M, Brandemuehi MJ, Schroeder C, Jeannette E (1999) Techniques for measuring and controlling outside air intake rates in variable air volume systems. Final Report of ASHRAE Research Project RP-980, ASHRAE, Atlanta.

Lagus Applied Technologies (1995) Air change rates in non-residential buildings in California, Report P400-91-034BCN, California Energy Commission, Sacramento, CA.

Orme, M. (1998) Energy impact of ventilation, Technical Note 49, International Energy Agency - Air Infiltration and Ventilation Centre, Coventry, Great Britain.

Persily A (1989) Ventilation rates in office buildings. Proceedings of the IAQ'89 Conference The Human Equation: Health and Comfort, pp. 128-136., ASHRAE, Atlanta.

Schroeder CC, Krarti M, Brandemuehl MJ (2000) error analysis of measurement and control techniques of outside air intake rates in VAV systems. ASHRAE Transactions 106(2): *** * ***

Turk, B.H., Brown J.T., Geisling-Sobatka, K., Froelich, D.A., Grimsrud, D.T., Harrison, J., Koonce, J.F., Prill, R.J., and Revzan, K.L. (1987) Indoor Air Quality and Ventilation Measurements in 38 Pacific Northwest Commercial Buildings--Volume 1: Measurement Results and Interpretation, Lawrence Berkeley Laboratory Report, LBL-22315 1/2, Berkeley, CA. 